\title{
Chapter 4: Ethics and Learning Analytics: Charting the (Un)Charted
}

\author{
Paul Prinsloo, ${ }^{1}$ Sharon Slade ${ }^{2}$ \\ ${ }^{1}$ Department of Business Management, University of South Africa, South Africa \\ ${ }^{2}$ Faculty of Business and Law, The Open University, United Kingdom
}

DOI: $10.18608 /$ hla17.004

\begin{abstract}
As the field of learning analytics matures, and discourses surrounding the scope, definition, challenges, and opportunities of learning analytics become more nuanced, there is benefit both in reviewing how far we have come in considering associated ethical issues and in looking ahead. This chapter provides an overview of how our own thinking has developed and maps our journey against broader developments in the field. Against a backdrop of technological advances and increasing concerns around pervasive surveillance and the role and unintended consequences of algorithms, the development of research in learning analytics as an ethical and moral practice provides a rich picture of fears and realities. More importantly, we begin to see ethics and privacy as crucial enablers within learning analytics. The chapter briefly locates ethics in learning analytics in the broader context of the forces shaping higher education and the roles of data and evidence before tracking our personal research journey, highlighting current work in the field, and concluding by mapping future issues for consideration.
\end{abstract}

Keywords: Ethics, artificial intelligence, data, big data, students

In 2011, the New Media Consortium's Horizon Report (NMC, 2011) pointed to the increasing importance of learning analytics as an emerging technology, which has since developed from a mid-range technology or trend to one to be realized within a "one year or less" time-frame (NMC 2016, p. 38). Though there are clear linkages between learning analytics and the more established field of educational data mining, there are also important distinctions regarding, inter alia, automation, aims, origins, techniques, and methods (Siemens \& Baker, 2012). As the field of learning analytics has developed as a distinct field of research and practice (see van Barneveld, Arnold, \& Campbell, 2012), so too thinking around ethical issues has slowly moved in from the margins. Slade and Prinsloo (2013) established one of the earliest frameworks developed with a focus on ethics in learning analytics. Since then, the number of authors publishing in this sub-field has significantly increased, resulting in a growing number of frameworks, codes of practices, taxonomies, and guidelines (Gašević, Dawson \& Jovanović, 2016).

In the wider context of public concerns surrounding increasing surveillance and the (un)warranted collection, analysis, and use of personal data, "fears and realities are often indistinguishably mixed up, leading to an atmosphere of uncertainty among potential beneficiaries" (Drachsler \& Greller, 2016, p. 89). Gašević et al. (2016) also suggest that further challenges remain "to be addressed in order to further aid uptake and integration into educational practice," and see ethics and privacy as important enablers to the field of learning analytics "rather than barriers" (p. 2).

We briefly situate set the context for considering the ethical implications of learning analytics, before mapping our personal research journey in the field. We then consider recent developments and conclude by flagging a selection of issues that continue to require broader and more critical engagement.

\section{SETTING THE CONTEXT: WHY ETHICS IS RELEVANT}

There is some consensus that the future of learning will be digital, distributed, and data-driven such that 
education "enables quality of life and meaningful employment through (a) exceptional quality research; (b) sophisticated data collection and; (c) advanced machine learning and human learning analysis/ support" (Siemens, 2016, Slide 2). Although considerations of the ethical implications of learning analytics were initially on the margins of the field, the prominence of ethics has come a long way and is increasingly foregrounded (Gašević et al., 2016). In a context where much is to be said for the potential economic benefits (for both students and the institution) of more successful learning experiences resulting from increased data harvesting, we should not ignore the possibilities of "data-proxy-induced hardship... when the detail obtained from the data-proxy comes to disadvantage its embodied referent in some way" (Smith, 2016, p. 16; also see Ruggiero, 2016; Strauss, 2016b; and Watters, 2016).

Ethical implications around the collection, analysis, and use of student data should take cognizance of the potentially conflicting interests and claims of a range of stakeholders, such as students and institutions. Views on the benefits, risks, and potential for harm resulting from the collection, analysis, and use of student data will depend on the interests and perceptions of the particular stakeholder. In this chapter, we hope to provide insight into the different positionalities, claims, and interests of primarily students and institutions.

\section{ESTABLISHING ETHICAL PRINCI- PLES: HOW FAR HAVE WE COME?}

Although now becoming more established, ethics and the need to question how student data is used and under what conditions was very much a marginal issue in the early years of the field. The first attempts to explore wider issues around learning analytics were presented at LAK '12 in Vancouver. The large majority of sessions at this conference remained focused on developmental work. There was some mention of stakeholder perceptions of the ways in which student data could be used, notably Drachsler and Greller (2012), though their paper suggested that surveyed stakeholder considerations were largely focused on privacy and not considered particularly contentious. A further paper (Prinsloo, Slade, \& Galpin, 2012) touched upon the need to consider the impacts of all stakeholders on students' learning journeys in order to increase the success of students' learning. The notion of "thirdspace" provided a useful heuristic to map the challenges and opportunities, but also the paradoxes of learning analytics and its potential impact on student success and retention. At the same conference, an exploratory workshop (Slade \& Galpin, 2012) built upon early work by Campbell, DeBlois, and Oblinger (2007) aiming to consider and expand upon a number of assumed relevant ethical issues from different stakeholder perspectives.

Work in 2013 moved onto an examination of existing institutional policy frameworks that set out the purposes for how data would be used and protected (Prinsloo \& Slade, 2013). The growing advent of learning analytics had seen uses of student data expanding rapidly. In general, policies relating to institutional use of student data had not kept pace, nor taken account of the growing need to recognize ethical concerns, focusing mainly on data governance, data security, and privacy issues. The review identified clear gaps and the insufficiency of existing policy.

Taking a sociocritical perspective on the use of learning analytics, Slade and Prinsloo (2013) considered a number of issues affecting the scope and definition of the ethical use of learning analytics. A range of ethical issues was grouped within three broad, overlapping categories, namely:

- The location and interpretation of data

- Informed consent, privacy, and the de-identification of data

- The management, classification, and storage of data Slade and Prinsloo (2013) proposed a framework based on the following six principles:

1. Learning analytics as moral practice - focusing not only on what is effective, but on what is appropriate and morally necessary

2. Students as agents - to be engaged as collaborators and not as mere recipients of interventions and services

3. Student identity and performance as temporal dynamic constructs - recognizing that analytics provides a snapshot view of a learner at a particular time and context

4. Student success as a complex, multidimensional phenomenon

5. Transparency as important - regarding the purposes for which data will be used, under what conditions, access to data, and the protection of an individual's identity

6. That higher education cannot afford not to use data

These principles offer a useful starting position, but ought sensibly to be supported by consideration of a number of practical considerations, such as the development of a thorough understanding of who benefits (and under what conditions); establishment of institutional positions on consent, de-identification and opting out; issues around vulnerability and harm (e.g., inadvertent labelling); systems of redress (for both student and institution); data collection, analyses, 
access, and storage (e.g., security issues and avoiding perpetuation of bias); and governance and resource allocation (including clarity around the key drivers for "success" (and what success means), existing constraints, and the conditions that must be met).

This latter aspect of resource allocation was carefully explored in a later paper considering the concept of educational triage (Prinsloo \& Slade, 2014a). Although learning analytics offers theoretical opportunities for HEIs (higher education institutions) to proactively identify and support students at risk of failing or dropping out, they do so in a context whereby resources are (increasingly) limited. The challenge then is where best to direct support resources and on what basis that decision is made. The concept of educational triage as a means of directing support toward students most likely to "survive" requires careful consideration of a number of related and complex issues, such as the balance between respecting student autonomy and, at the same time, ensuring the long-term sustainability of the institution; the notion of beneficence (to always act in the student's best interest); the need for non-maleficence (inflicting the least harm possible to reach a beneficial outcome); and maintaining a sense of distributive justice (understanding that demographic characteristics have and do impact support provided and assumptions made, and the need to recognize and address this).

An increasing awareness of learning analytics as a means of doing something to the student without that student necessarily knowing triggered further exploration of issues around surveillance, student privacy and institutional accountability (Prinsloo \& Slade, 2014b). The resulting discussion challenged assumptions around learning analytics as a producer of accurate, objective, fully complete pictures of student learning, and also reviewed the potentially unequal relationship between institution and student. In considering existing frameworks regarding the use and analysis of personal data, the study suggested six elements that could form a basis for a student-centred learning analytics:

1. The use of aggregated, non-personalized data is essential in delivering effective and appropriate teaching and learning, but students should be able to make informed opt in/out decisions

2. Students should have full(er) knowledge of which data is collected and how it is used

3. Students should ensure that their personal data records are complete and up to date

4. The surveillance of activities and the harvesting of data must not harm student progress

5. Algorithmic output should be subject to (potential) human review, and corrected if needed

6. Learning analytics essentially provides context and time-specific, provisional, incomplete pictures of students, and algorithms should be frequently reviewed and validated

Issues around surveillance and the need to recognize students as active agents in the use of their own data was explicitly addressed within the development of The Open University (OU; 2014) policy on the ethical use of student data for learning analytics. As part of the stakeholder consultation, a representative group of 50 students explored their understanding of the ways in which data is used to support students in completing their study goals over a three-week period. A study of responses (Slade \& Prinsloo, 2014) found that students appeared largely unaware of the extent to which data was already actively collected and used, and they raised a number of concerns. The major concern related to the potential to actively consent (or not), with a majority of students expressing a wish for a right to opt out. This direct involvement of student voices in shaping a policy dealing with the ethics of learning analytics offered unique insight into the ways in which students regard their data - as a valuable entity to be carefully protected and even more carefully applied. Given that the sample in Slade and Prinsloo (2014) may not be fully representative of the total population, the outcomes cannot be generalized across institutional and geopolitical contexts.

In response to this growing awareness of student concern, Prinsloo and Slade (2015) questioned whether our assumptions and understanding of issues surrounding student attitudes to privacy may be influenced by both the apparent ease with which the public appear to share the detail of their lives and by our largely paternalistic institutional cultures. The study explored issues around consent and the seemingly simple choice to allow students to opt-in or opt-out of having their data tracked. As a foundation for the discussion, the terms and conditions of three massive open online course (MOOC) providers were reviewed to establish information given to users regarding the uses of their data. This extended into a discussion of how HEIs can move toward an approach that engages and more fully informs students of the implications of learning analytics on their personal data. A similar theme was pursued in Prinsloo and Slade (2016a). This paper challenged the tendency for many HEIs to adopt an authoritarian approach to student data. Despite the rapid growth in the deployment of learning analytics, few HEIs have regulatory frameworks in place and/or are fully transparent regarding the scope of student data collected, analyzed, used, and shared. Student vulnerability was explored in the nexus be- 
tween realizing the potential of learning analytics; the fiduciary duty of HEIs in the context of their asymmetrical information and power relations with students; and the complexities surrounding student agency in learning analytics. The aim was to consider ways in which student vulnerability may be addressed, increasing student agency, and empowering them as active participants in learning analytics - moving from quantified data objects to qualified and qualifying selves (see also Prinsloo \& Slade, 2016b).

\section{RECENT DEVELOPMENTS IN ETHICAL FRAMEWORKS}

It is broadly accepted that the increasing value of data as a sharable commodity with an increasing exchange value has overtaken our legal and traditional ethical frameworks (Zhang, 2016). "Deep economic pressures are driving the intensification of connection and monitoring online" (Couldry, 2016, par. 13) and "What's needed is more collective reflection on the costs of capitalism's new data relations for our very possibilities of ethical life" (Couldry, 2016, par. 35). As such, there have been attempts in different geopolitical and institutional contexts to grapple with the ethical implications of learning analytics. Sclater, Peasgood, and Mullan (2016), for example, review practices within higher education in the United States, Australia, and the United Kingdom. They summarize their findings by indicating that learning analytics makes significant contributions for 1) quality assurance and quality improvement; 2) boosting retention rates; 3) assessing and acting upon differential outcomes among the student population; and 4) the development and introduction of adaptive learning. The report acknowledges the many opportunities, but also highlights threats such as "ethical and data privacy issues, 'over-analysis' and the lack of generalizability of the results, possibilities for misclassification of patterns, and contradictory findings" (p. 16). In their review, the one institutional example of a policy level bid to address the ethical concerns in learning analytics is that of The Open University (UK). In 2014, the OU published a "Policy on ethical use of student data for learning analytics" delimiting the nature and scope of data collected and analyzed and an explicit specification of data that will not be collected and used for learning analytics. The policy establishes the following eight principles (p. 6):

1. Learning analytics is an ethical practice that should align with core organizational principles, such as open entry to undergraduate level study.

2. The OU has a responsibility to all stakeholders to use and extract meaning from student data for the benefit of students where feasible.

3. Students should not be wholly defined by their visible data or our interpretation of that data. [This principle furthermore warns against stereotyping students and acknowledges those individuals who do not fit into typical patterns. The principle also makes it clear that members of staff may not have access to the full data set, which can seriously impact the reliability of the analysis.]

4. The purpose and the boundaries regarding the use of learning analytics should be well defined and visible.

5. The University is transparent regarding data collection, and will provide students with the opportunity to update their own data at regular intervals.

6. Students should be engaged as active agents in the implementation of learning analytics (e.g., informed consent, personalized learning paths, interventions).

7. Modelling and interventions based on analysis of data should be sound and free from bias.

8. Adoption of learning analytics within the OU requires broad acceptance of the values and benefits (organizational culture) and the development of appropriate skills across the organization.

As one of the first institutional responses to the ethical implications in the collection, analysis, and use of student data, this policy and its principles attempted to map uncharted territory. Of specific interest is the definition of "informed consent" as referring to "the process whereby the student is made aware of the purposes to which some or all of their data may be used for learning analytics and provides consent. Informed consent applies at the point of reservation or registration on to a module or qualification" (Open University, 2014, p. 3). The policy does not address the possibility of students who prefer to opt out of the collection, analysis, and use of their data (as discussed by Engelfriet, Manderveld, \& Jeunink, 2015; Sclater, 2015; also see Shacklock, 2016).

In a recent overview of learning analytics practices in the Australian context, Dawson, Gašević, and Rogers (2016) report that the "relative silence afforded to ethics across the studies is significant" (p. 3) and that this "does not reflect the seriousness with which the sector should consider these issues" (p. 33). The report suggests that "It is likely that the higher education sector has not been ready for such a conversation previously, although it is argued that as institutions are maturing, ethical considerations take on a heightened salience" (p. 33).

Also in the Australian context, Welsh and McKinney (2015) position the need for a Code of Practice in learn- 
ing analytics in the context of the "relative immaturity of the discipline with institutions, practitioners and technology vendors still figuring out what works and finding the boundaries of 'acceptable' practice" and the real potential for abuse/misuse and discrimination (p. 588). Of particular importance is the commitment that "The University will not engage in Learning Analytics practices that use data sources: (a) not directly related to learning and teaching; and/or (b) where users may not reasonably expect such data collection by the University to occur" (p. 590). Student data will only be used in the context of the original purpose for which the data in question was collected; its use can continue under the following conditions:

Explicit informed consent is gathered from those who are the subject of measurement. Where informed consent means that: (a) clear and accurate information is provided about what data is or may be collected, why and how it is collected, how it is stored and how it is used; and (b) agreement is freely given to the practice(s) described. (p. 590)

The above principles should be read in conjunction with two remaining principles regarding how collected data should be used to enhance teaching and learning and to give students "greater control over and responsibility for their learning" (p. 591); and one of transparency and informed participation. For a full discussion, see Welsh and McKinney (2015).

Drachsler and Greller (2016) provide a broad overview of ethics, privacy, and respective legal frameworks, and highlight challenges such as the real possibility of exploitation in light of the asymmetrical power relationship between data gatherer and data object, issues of ownership, anonymity and data security, privacy and data identity, as well as transparency and trust. They present a checklist (DELICATEC) to ensure that learning analytics proceeds in an acceptable and compliant way "to overcome the fears connected to data aggregation and processing policies" (p. 96).

Sclater (2015) proposes a (draft) taxonomy of ethical, legal, and logistical issues in learning analytics with an overview of how a range of stakeholders, such as senior management, the analytics committee, data scientists, educational researchers, IT, and students are impacted and have responsibility in learning analytics. The draft covers a wide range of issues including, inter alia, consent; identity; potential impacts of opting out; the asymmetrical relationship between the institution and students; (boundaries around) the permissible uses of student data; transparency; data included (and excluded) from use; and student autonomy, amongst others. See Sclater (2015) for a full list of ethical concerns.
In the Dutch higher education context, Engelfriet et al. (2015) consider the implications of the Law for the Protection of Personal Information for learning analytics. These include the need for permission (and the responsibility arising from receiving consent) and the implications of the consensual agreement between a service provider and recipient that the provider may use any personal information needed for the provision of the service. The law distinguishes between essential information and "handy" information. Engelfriet et al. (2015) take a contentious view that, given that learning analytics is seen as an emerging practice, it may safely be regarded as collecting "handy" information, and so perhaps excluded from the need for consensual agreement between the institution and students. The authors suggest that these four principles should guide learning analytics:

- $\quad$ Personal information be used only in the context and purpose for which it was provided

- $\quad$ Subsequent use of such data should be reconcilable with the original context and purpose

- $\quad$ Data should be carefully collected and analyzed, and "sneaky" ("stiekeme" in Dutch) usage of analytics is not permissible; this appears to emphasize a need for transparency, student consultation, and buy in

- Data may only be collected when the purpose/ use of the collected data is made explicitly clear

Engelfriet et al. (2015) explore student rights around the governance of their data, including the following:

\section{- $\quad$ Easy access to collected information}

- The right to correct wrong information (or interpretations arising from it)

- The right to remove irrelevant information

Of particular interest is an exploration of the ethical implications for algorithmic decision making and the authors flag examples that lead to potential conflict with Dutch law. The implication is that humans need to take responsibility for and have oversight of algorithmic decision making. Algorithms may, at most, signal particular behaviour for the attention of faculty or support staff. Further, students have a right to appeal decisions made based on analyses of their personal data. In cases where HEIs subcontract to software developers, the final responsibility and oversight remains securely with the institution and cannot be delegated (see Engelfriet et al., 2015).

\section{SOME FUTURE CONSIDERATIONS}

It falls outside the scope of this chapter to map current and future gaps in our understanding of the complexities and practicalities at the intersections between 
student data and advances in technology and methods of analysis. We would like to conclude, however, with some pointers for future consideration.

Given the mandate of higher education institutions to ensure effective, appropriate, cost-effective learning experiences and to support students to be successful, there is broad agreement that institutions have a right to collect and use student information. However, there is no easily agreed upon position around consent, that is, in allowing students to opt out of the collection, analysis, and use of their data. Student positions around consent may be influenced by issues not wholly logical or rational. The often-implicit calculation of benefits, costs, and risks will depend on a range of factors such as, inter alia, previous experiences, need, and perceived benefits (see, for example, Daniel Pink in O'Brien. 2010).

One recent example of opt out was led by the National Center for Fair and Open Testing in the US who encouraged students to refuse to take government-mandated standardized tests. Around 650,000 students opted out in the 2014-2015 school year (FairTest, n.d.), with the US Department of Education responding by threatening to withhold funding (Strauss, 2016a).

Further research is needed to explore potential conflicts between students' concerns, their right to opt-out, and the implications for the mandate of higher education to use student data to make interventions at an individual level. Central to this issue is the question of "who benefits?" (see Watters, 2016). Any consideration of the ethics around the collection, analysis, and use of student data (whether in learning analytics or in formal assessments) should also recognize the contesting claims and vested interests.

In the broader context of online research, Vitak, Shilton, and Ashktorab (2016) point to various challenges regarding ethical research practices in online contexts, such as the increasing and persisting concerns about re-identification: "researchers still struggle to balance research ethics considerations with the use of online datasets" (p. 1). Interestingly, their findings also show that many the researchers go beyond the Belmont principles (with the main emphasis on ensuring that outcomes outweigh potential harms caused by the research) by referring to "(1) transparency with participants, (2) ethical deliberation with colleagues, and (3) caution in sharing results" (par. 66).

There is also increasing concern balancing optimism around artificial intelligence (AI), machine learning, and big data. For example, the Executive Office of the President of the US released a report (Munoz, Smith, \& Patil, 2016) that highlights benefits, but also addresses concerns regarding the potential harm inherent in the use of big data. The report recognizes that if "these technologies [algorithmic systems] are not implemented with care, they can also perpetuate, exacerbate, or mask harmful discrimination" (p. 5). It makes a number of suggestions relating to investment in research into the mitigation of algorithmic discrimination, encouraging the development and use of robust and transparent algorithms, algorithmic auditing, improvements in data science "fluency," and the roles of the government and private sector in setting codes of practice around data use.

Similarly, the UK Government recently released a "Data science ethical framework" (Cabinet Office, 2016) providing guidance on "ethical issues which sit outside the law" (p. 3). The framework explores issues such as the nature of the benefits of the collection, analysis, and use of personal data; the scope and nature of intrusion; the quality of the data and the automation of the decisions relating to the collected data; the risk of negative unintended consequences; whether the data objects agreed to the collection and analysis; the nature and scope of the oversight; and the security of the collected data. The framework also proposes a "Privacy Impact Assessment" requiring data scientists to clarify "tricky issues" (p. 6), such as reviewing the extent to which the benefits of the project outweigh the risks to privacy and negative unintended consequences; steps undertaken to minimize risks and ensure correct interpretation; and the extent to which the opinions of the data objects/public regarding the project were considered (see Cabinet Office, 2016).

In the context of the algorithmic turn in (higher) education, and the increasing blurring of the boundaries between broader developments in data and neuroscience, we need a critical approach to considering the ethical implications of learning analytics as we find our way through the myth, mess, and methods (Ziewitz, 2016) of student data. For example, Williamson (2016a) considers "educational data science as a biopolitical strategy focused on the evaluation and management of the corporeal, emotional and embrained lives of children" (p. 401, emphasis added). As such, we have to consider the basis and scope of authority of educational data scientists who have "increasing legitimate authority to produce systems of knowledge about children and to define them as subjects and objects of intervention" (Williamson, 2016a, p. 401). Learning analytics in future will be essentially based on and driven by algorithms and machine learning and we therefore have to consider how algorithms "reinforce, maintain, or even reshape visions of the social world, knowledge, and encounters with information" (Williamson, 2016b, p. 4). Accountability, transparency, and regulatory frameworks will be essential elements in the frameworks ensuring ethical learning analytics (see Prinsloo, 2016; Taneja, 2016). 
While this chapter maps the progress in considering the ethical implications of the collection, analysis, and use of student data, it is clear that the potential for harm will not be addressed without further consideration of institutional processes to ensure accountability and transparency. As Willis, Slade, and Prinsloo (2016) indicate, learning analytics often falls outside the processes and oversight provided by institutional review boards (IRBs). It is not clear at this stage by whom and how the ethical implications of learning analytics will be assured.

\section{(IN)CONCLUSIONS}

Since the emergence of learning analytics in 2011, the field has not only matured, but also become more nuanced in increasingly considering the fears and realities of ethical implications in the collection, analysis, and use of student data. In this chapter, we provide an overview of how our own thinking has developed alongside broader developments in the field. Against a backdrop of technological advances and increasing concerns around pervasive surveillance, and a growing consensus that the future of higher education will be digital, distributed, and data-driven, this chapter maps how far the discourses surrounding the ethical implications of learning analytics have come, as well as some of the future considerations.

Each of the frameworks, code of practices, and conceptual mappings of the ethical implications in learning analytics discussed adds a further layer and a richer understanding of how we may move toward using student data-proxies to increase the effectiveness and appropriateness of teaching, learning, and student support strategies in economically viable and ethical ways. The practical implementation of that understanding remains largely incomplete, but still wholly pertinent.

\section{ACKNOWLEDGEMENTS}

We would like to acknowledge the comments, critical inputs, and support received from the editorial team and specially the reviewers of this chapter.

\section{REFERENCES}

Cabinet Office. (2016, 19 May). Data science ethical framework. https://www.gov.uk/government/uploads/ system/uploads/attachment_data/file/524298/Data_science_ethics_framework_v1.0_for_publication__1_.pdf

Campbell, J. P., DeBlois, P. B., \& Oblinger, D. G. (2007, July/August) Academic analytics: A new tool, a new era. EDUCAUSE Review. http://net.educause.edu/ir/library/pdf/erm0742.pdf

Couldry, N. (2016, September 23). The price of connection: "Surveillance capitalism." [Web log post]. https:// theconversation.com/the-price-of-connection-surveillance-capitalism-64124

Dawson, S., Gašević, D., \& Rogers, T. (2016). Student retention and learning analytics: A snapshot of Australian practices and a framework for advancement. Australian Government. http://he-analytics.com/wp-content/uploads/SP13_3249_Dawson_Report_2016-3.pdf

Drachsler, H., \& Greller, W. (2012). The pulse of learning analytics understandings and expectations from the stakeholders. Proceedings of the $2^{\text {nd }}$ International Conference on Learning Analytics and Knowledge (LAK '12), 29 April-2 May 2012, Vancouver, BC, Canada (pp. 120-129). New York: ACM.

Drachsler, H., \& Greller, W. (2016, April). Privacy and analytics: It's a DELICATE issue - a checklist for trusted learning analytics. Proceedings of the $6^{\text {th }}$ International Conference on Learning Analytics and Knowledge (LAK '16), 25-29 April 2016, Edinburgh, UK (pp. 89-98). New York: ACM.

Engelfriet, A., Manderveld, J., \& Jeunink, E. (2015). Learning analytics onder de Wet bescherming persoonsgegevens. SURFnet. https://www.surf.nl/binaries/content/assets/surf/nl/kennisbank/2015/surf_learning-analytics-onder-de-wet-wpb.pdf

FairTest. (n.d.). Just say no to the test. http://www.fairtest.org/get-involved/opting-out

Gašević, D., Dawson, S., \& Jovanović, J. (2016). Ethics and privacy as enablers of learning analytics. Journal of Learning Analytics, 3(1), 1-4. http://dx.doi.org/10.18608/jla.2016.31.1

Munoz, C., Smith, M., \& Patil, D. J. (2016). Big data: A report on algorithmic systems, opportunity, and civil rights. Executive Office of the President, USA. https://www.whitehouse.gov/sites/default/files/micro- 
sites/ostp/2016_0504_data_discrimination.pdf

NMC (New Media Consortium). (2011). The NMC Horizon Report. http://www.educause.edu/Resources/2011HorizonReport/223122

NMC (New Media Consortium). (2016). The NMC Horizon Report. http://www.nmc.org/publication/ nmc-horizon-report-2016-higher-education-edition/

O'Brien, A. (2010, September 29). Predictably irrational: A conversation with best-selling author Dan Ariely. [Web log post]. http://www.learningfirst.org/predictably-irrational-conversation-best-selling-author-dan-ariely

Open University. (2014). Policy on ethical use of student data for learning analytics. http://www.open. ac.uk/students/charter/sites/www.open.ac.uk.students.charter/files/files/ecms/web-content/ethical-use-of-student-data-policy.pdf

Prinsloo, P. (2016, September 22). Fleeing from Frankenstein and meeting Kafka on the way: Algorithmic decision-making in higher education. Presentation at NUI, Galway. http://www.slideshare.net/prinsp/feeling-from-frankenstein-and-meeting-kafka-on-the-way-algorithmic-decisionmaking-in-higher-education

Prinsloo, P., Slade, S., \& Galpin, F. (2012) Learning analytics: Challenges, paradoxes and opportunities for mega open distance learning institutions. Proceedings of the $2^{\text {nd }}$ International Conference on Learning Analytics and Knowledge (LAK '12), 29 April-2 May 2012, Vancouver, BC, Canada (pp. 130-133). New York: ACM.

Prinsloo, P., \& Slade, S. (2013). An evaluation of policy frameworks for addressing ethical considerations in learning analytics. Proceedings of the $3^{\text {rd }}$ International Conference on Learning Analytics and Knowledge (LAK '13), 8-12 April 2013, Leuven, Belgium (pp. 240-244). New York: ACM.

Prinsloo, P., \& Slade, S. (2014a). Educational triage in higher online education: Walking a moral tightrope. International Review of Research in Open Distributed Learning (IRRODL), 14(4), 306-331. http://www.irrodl.org/ index.php/irrodl/article/view/1881

Prinsloo, P., \& Slade, S. (2014b). Student privacy and institutional accountability in an age of surveillance. In M. E. Menon, D. G. Terkla, \& P. Gibbs (Eds.), Using data to improve higher education: Research, policy and practice (pp. 197-214). Global Perspectives on Higher Education (29). Rotterdam: Sense Publishers.

Prinsloo, P., \& Slade, S. (2015). Student privacy self-management: Implications for learning analytics. Proceedings of the 5th International Conference on Learning Analytics and Knowledge (LAK '15), 16-20 March 2015, Poughkeepsie, NY, USA (pp. 83-92). New York: ACM.

Prinsloo, P., \& Slade, S. (2016a). Student vulnerability, agency, and learning analytics: An exploration. Journal of Learning Analytics, 3(1), 159-182.

Prinsloo, P., \& Slade, S. (2016b). Here be dragons: Mapping student responsibility in learning analytics. In M. Anderson \& C. Gavan (Eds.), Developing effective educational experiences through learning analytics (pp. 170-188). Hershey, PA: IGI Global.

Ruggiero, D. (2016, May 18). What metrics don't tell us about the way students learn. The Conversation. http:// theconversation.com/what-metrics-dont-tell-us-about-the-way-students-learn-59271

Sclater, N. (2015, March 3). Effective learning analytics. A taxonomy of ethical, legal and logistical issues in learning analytics v1.0. JISC. https://analytics.jiscinvolve.org/wp/2015/03/03/a-taxonomy-of-ethical-legal-and-logistical-issues-of-learning-analytics-v1-0/

Sclater, N., Peasgood, A., \& Mullan, J. (2016). Learning analytics in higher education. A review of UK and international practice. JISC. https://www.jisc.ac.uk/reports/learning-analytics-in-higher-education

Shacklock, X. (2016). From bricks to clicks: The potential of data and analytics in higher education. Higher Education Commission. http://www.policyconnect.org.uk/hec/sites/site_hec/files/report/419/fieldreportdownload/frombrickstoclicks-hecreportforweb.pdf

Siemens, G. (2016, April 28). Reflecting on learning analytics and SoLAR. [Web log post]. http://www.elearnspace.org/blog/2016/04/28/reflecting-on-learning-analytics-and-solar/ 
Siemens, G., \& Baker, R. (2012, April). Learning analytics and educational data mining: Towards communication and collaboration. Proceedings of the $2^{\text {nd }}$ International Conference on Learning Analytics and Knowledge (LAK '12), 29 April-2 May 2012, Vancouver, BC, Canada (pp. 252-254). New York: ACM.

Slade, S., \& Galpin, F. (2012) Learning analytics and higher education: Ethical perspectives (workshop). Proceedings of the $2^{\text {nd }}$ International Conference on Learning Analytics and Knowledge (LAK '12), 29 April-2 May 2012, Vancouver, BC, Canada (pp. 16-17). New York: ACM.

Slade, S., \& Prinsloo, P. (2013). Learning analytics: Ethical issues and dilemmas. American Behavioral Scientist, 57(1), 1509-1528.

Slade, S., \& Prinsloo, P. (2014). Student perspectives on the use of their data: Between intrusion, surveillance and care. Proceedings of the European Distance and E-Learning Network 2014 Research Workshop (EDEN 2014), 27-28 October 2014, Oxford, UK (pp. 291-300).

Smith, G. J. (2016). Surveillance, data and embodiment: On the work of being watched. Body E Society, 1-32. doi:10.1177/1357034X15623622

Strauss, V. (2016a, January 28). U.S. Education Department threatens to sanction states over test opt-outs. The Washington Post. https://www.washingtonpost.com/news/answer-sheet/wp/2016/01/28/u-s-education-department-threatens-to-sanction-states-over-test-opt-outs /

Strauss, V. (2016b, May 9). "Big data" was supposed to fix education. It didn't. It's time for "small data." The Washington Post. https://www.washingtonpost.com/news/answer-sheet/wp/2016/05/09/big-datawas-supposed-to-fix-education-it-didnt-its-time-for-small-data/

Taneja, H. (2016, September 8). The need for algorithmic accountability. TechCrunch. https://techcrunch. com/2016/09/08/the-need-for-algorithmic-accountability/

van Barneveld, A., Arnold, K., \& Campbell, J. (2012). Analytics in higher education: Establishing a common language. EDUCAUSE Learning Initiative, 1, 1-11.

Vitak, J., Shilton, K., \& Ashktorab, Z. (2016). Beyond the Belmont principles: Ethical challenges, practices, and beliefs in the online data research community. Proceedings of the $19^{\text {th }}$ ACM Conference on Computer Supported Cooperative Work E Social Computing (CSCW '16), 27 February-2 March 2016, San Francisco, CA, USA. New York: ACM. https://terpconnect.umd.edu/ kshilton/pdf/VitaketalCSCWpreprint.pdf

Watters, A. (2016, May 7). Identity, power, and education's algorithms. [Web log post]. http://hackeducation. com/2016/05/07/identity-power-algorithms

Welsh, S., \& McKinney, S. (2015). Clearing the fog: A learning analytics code of practice. In T. Reiners et al. (Eds.), Globally connected, digitally enabled. Proceedings of the $32^{\text {nd }}$ Annual Conference of the Australasian Society for Computers in Learning in Tertiary Education (ASCILITE 2015), 29 November-2 December 2015, Perth, Western Australia (pp. 588-592). http://research.moodle.net/80/

Williamson, B. (2016a). Coding the biodigital child: The biopolitics and pedagogic strategies of educational data science. Pedagogy, Culture \& Society, 24(3), 401-416. doi:10.1080/14681366.2016.1175499

Williamson, B. (2016b). Computing brains: Learning algorithms and neurocomputation in the smart city. Information, Communication E Society, 20(1), 81-99. doi:10.1080/1369118X.2016.1181194

Willis, J., Slade, S., \& Prinsloo, P. (2016). Ethical oversight of student data in learning analytics: A typology derived from a cross-continental, cross-institutional perspective. Educational Technology Research and Development. doi:10.1007/s11423-016-9463-4

Zhang, S. (2016, May 20). Scientists are just as confused about the ethics of big data research as you. Wired. http://www.wired.com/2016/05/scientists-just-confused-ethics-big-data-research/

Ziewitz, M. (2016). Governing algorithms: Myth, mess, and methods. Science, Technology E Human Values, 41(1), 3-16. 